\title{
DESAFIOS NO ATENDIMENTO AOS CASOS DE VIOLÊNCIA DOMÉSTICA CONTRA A MULHER EM UM MUNICÍPIO MATOGROSSENSE
}

\author{
Vagner Ferreira do Nascimento ${ }^{1}$ \\ Tamires Fortunato de Lima Rosa ${ }^{2}$ \\ Ana Cláudia Pereira Terças ${ }^{3}$ \\ Thalise Yuri Hattori ${ }^{4}$ \\ Valéria Ferreira do Nascimento 5
}

\begin{abstract}
NASCIMENTO, V. F. do; ROSA, T. F. de L.; TERÇAS, A. C. P.; HATTORI, T. Y.; NASCIMENTO. V. F. do. Desafios no atendimento à casos de violência doméstica contra a mulher em um município matogrossense. Arq. Cienc. Saúde UNIPAR, Umuarama, v. 23, n. 1, p, 15-22, jan./abr. 2019.
\end{abstract}

\begin{abstract}
RESUMO: O estudo objetivou identificar os principais desafios do atendimento aos casos de violência doméstica contra mulheres em um município de Mato Grosso. Trata-se de estudo descritivo, exploratório e com abordagem qualitativa. Realizado com oito profissionais de Estratégias de Saúde da Família. A coleta de dados ocorreu no período de dezembro de 2017 a janeiro de 2018, por meio de entrevistas gravadas, guiadas por questão norteadora aberta correspondente ao objetivo do estudo. A partir das narrativas, empregou-se a análise de conteúdo, do tipo temática. A identificação de casos de violência pelos profissionais do estudo parece ser uma tarefa complexa e limitante; circunstância que dificulta a implementação de uma assistência mais efetiva. A Estratégia de Saúde da Família é vista como uma porta de entrada favorável à identificação dos casos de violência, contudo, percebe-se a dificuldade dos profissionais em lidar e reconhecer esse tipo de agravo. Com o estudo, foi possível evidenciar alguns obstáculos encontrados pelos profissionais na identificação de casos de violência doméstica, assim como os enfrentamentos diante de denúncias e acompanhamento dos envolvidos.
\end{abstract}

PALAVRAS-CHAVE: Violência Doméstica. Atenção Primária à Saúde. Acolhimento.

\section{CHALLENGES REGARDING CASES OF DOMESTIC VIOLENCE AGAINST WOMEN IN A CITY IN MATO GROSSO}

ABSTRACT: This study aimed at identifying the main challenges of attending to cases of domestic violence against women in a city in the state of Mato Grosso. This is a descriptive, exploratory study with a qualitative approach held with eight professionals from the Family Health Strategies. Data collection took place from December 2017 to January 2018 through recorded interviews, guided by an open-ended question corresponding to the study objective. Thematic content analysis was employed on the narratives. The identification of cases of violence by the analyzed professionals seems to be a complex and limiting task; which makes it difficult to implement more effective assistance. The Family Health Strategy is seen as a favorable entry point for the identification of cases of violence; however, the difficulty of professionals in dealing with and recognizing that type of injury could be note. With the study, it was possible to emphasize some of the obstacles encountered by professionals in the identification of cases of domestic violence as well as the confrontations before complaints and follow-ups with those involved.

KEYWORDS: Domestic Violence. Primary Health Care. User Embracement.

\section{Introdução}

Frequentemente crianças, mulheres, homens e idosos têm sido alvo das mais diversas formas de violência no contexto intrafamiliar. Esses crimes, ocorrem com muita frequência e se enquadram no padrão de comportamento amplamente coberto pelo conceito de violência doméstica, que faz parte integrante da história da família das sociedades (MUSSE et al., 2015).

Assim, a violência doméstica é caracterizada como um problema crescente de saúde pública que gera grandes consequências, bem como danos irreversíveis ao indivíduo, família e comunidade (LIMA et al., 2017). Ao analisar a violência no âmbito familiar, deve ser considerada a desigualdade de gênero, especialmente no exercício da força e poder de um sobre o outro. É comum que as mulheres vítimas desse tipo de violência não revidem, por medo do agressor ou receio de sofrer humilhação perante a sociedade, já que se veem em sofrimento constante (GOMES et al., 2014).

A violência contra as mulheres está presente em todo o mundo, atinge todas as classes sociais e segundo a Organização Mundial da Saúde (OMS), 35\% das mulheres dos diferentes continentes são vítimas de algum tipo de violência, normalmente executada por seus parceiros afetivos (WHO, 2013). No Brasil, foram registrados no Sistema de Informações de Mortalidade (SIM) em 2016, um total de 57.395 óbitos de mulheres decorrentes de agressões (DATASUS, 2017). Em Mato Grosso, esse cenário é preocupante já que o estado é o primeiro do país no registro de casos de feminicídio e ocupada o segundo lugar em casos de violência contra a mulher (MATO GROSSO, 2018).

A violência doméstica contra a mulher começou a ser enfrentada como problema de saúde pública, pois impactam em custos socioeconômicos e prejuízos na saúde individual e coletiva da família (FONSECA et al., 2012). Diante disso, algumas legislações foram implementadas no Brasil,

DOI: 10.25110 /arqsaude.v23i1.2019.6625

${ }^{1}$ Enfermeiro. Doutor em BIOÉTICA. Docente Adjunto da Universidade do Estado de Mato Grosso (UNEMAT), Campus Universitário de Tangará da Serra, Departamento de Enfermagem.

${ }^{2}$ Enfermeira. Especialista em Saúde da Família. Docente Auxiliar da Universidade do Estado de Mato Grosso (UNEMAT), Campus Universitário de Tangará da Serra, Departamento de Enfermagem.

${ }^{3}$ Enfermeira. Doutora em Medicina Tropical. Docente Adjunta da Universidade do Estado de Mato Grosso (UNEMAT), Campus Universitário de Tangará da Serra, Departamento de Enfermagem.

${ }^{4}$ Enfermeira. Mestre em Ciências da Saúde. Docente Assistente da Universidade do Estado de Mato Grosso (UNEMAT), Campus Universitário de Tangará da Serra, Departamento de Enfermagem.

${ }^{5}$ Bacharel em Direito. Policial Civil do Governo do Estado de Mato Grosso do Sul. 
como a Lei Maria da Penha, esta que tornou-se um meio para represar a violência doméstica e familiar contra a mulher (BRASIL, 2006). Na referida lei, a violência doméstica contra a mulher é definida como qualquer ação ou omissão baseada no gênero que lhe cause morte, lesão, sofrimento físico, sexual ou psicológico e dano moral ou patrimonial. Esse marco histórico é uma grande conquista quando refere-se a violência doméstica, já que as punições começam a ser aplicadas aos agressores, a fim de reduzir e/ou exterminar os casos de violênci (GARCIA et al., 2013).

Entretanto, mesmo reconhecendo a importância desse marco legal como instrumento de intervenção na violência doméstica contra as mulheres, após onze anos de sua criação parece que as expectativas iniciais ainda não foram superadas, o que reforça a necessidade de buscar outras estratégias que não se restrinjam majoritariamente para o caráter punitivo (após o ato de violência), implementando ações direcionadas à promoção da cultura de paz, em todos os ciclos de vida, os quais apresentam vulnerabilidade à violência (GREIN et al., 2016; MACHADO et al., 2017). Além disso, há necessidade de capacitar os profissionais de saúde que atendem essas mulheres para uma atenção qualificada.

A abordagem das mulheres vítimas de violência doméstica deve estar pautada no tratamento ético e respeitoso, buscando o acolhimento como estratégia primordial, como prevê o Sistema Único de Saúde (SUS). Ressalta-se ainda a necessidade de articulação das redes de apoio, para o fluxo adequado de encaminhamento às delegacias especializadas e demais setores que se fizerem necessário (OLIVEIRA et al., 2018).

Nesse sentido, o estudo objetivou-se identificar os principais desafios no atendimento dos casos de violência doméstica contra a mulher em um município Matogrossense.

\section{Métodos}

Trata-se de estudo descritivo, exploratório e com abordagem qualitativa. $\mathrm{O}$ cenário de estudo constituiu-se em oito Estratégias de Saúde da Família (ESF) localizadas na área urbana de um munícipio da região médio norte de Mato Grosso. Este município possui população estimada em 98.828 pessoas, em uma área de $11.565,976 \mathrm{~km}^{2}$. Localiza-se na região sudoeste do estado de Mato Grosso, a $240 \mathrm{~km}$ de Cuiabá, capital de Mato Grosso (IBGE, 2017).

Os participantes do estudo foram sete enfermeiros e um médico, ambos integrantes das ESF (selecionadas aleatoriamente), que atenderam aos seguintes critérios de inclusão: estar vinculado a ESF (efetivo ou celetista) e possuir no mínimo um ano de atuação no município. Os critérios de exclusão utilizados foram, enfermeiros e/ou médicos em afastamento (férias e licenças diversas), bem como possuir formação acadêmica fora do Brasil, uma vez que estes possuem alta rotatividade, causando dificuldade na abordagem pela não fluência da língua portuguesa. Para definição do tamanho amostral, utilizou-se o método de saturação dos dados (FONTANELLA et al., 2011).

Os dados foram coletados nos meses de dezembro de 2017 a janeiro de 2018, por meio de entrevista individual gravada com uma questão norteadora que respondesse ao objetivo do estudo. Os participantes tiveram a oportunidade de explanar livremente, sem interferência do pesquisador, suas vivências frente ao atendimento dos casos de violência. As entrevistas tiveram duração média de 25 minutos, sendo realizadas no ambiente de escolha dos participantes, prevalecendo a própria ESF.

Ao término das entrevistas, as narrativas foram transcritas na íntegra, recebendo codificação do tipo alfanumérica, onde a consoante $P$ referiu aos participantes e o número arábico que ordenou o conjunto determinou a sequência da realização das entrevistas. Para análise do material empírico, utilizou-se a análise de conteúdo, do tipo temática. As linhas de análise partiram-se das fases: pré-análise, exploração do material, tratamento dos resultados: inferência e interpretação. A pré-análise consiste na organização do material a ser analisado com o objetivo de sistematizar as ideias iniciais; a exploração do material consiste na definição de categorias e identificação das unidades de registro e de contexto das falas das participantes; e o tratamento e interpretação dos resultados consistem no destaque das informações para análise, culminando nas interpretações inferenciais (BARDIN, 2011).

$\mathrm{O}$ estudo faz parte de uma pesquisa matricial intitulada "Violência contra mulher no município de Tangará da Serra, Mato Grosso", aprovada pelo Comitê de Ética em Pesquisa com Seres Humanos (CEP) da Universidade do Estado de Mato Grosso (UNEMAT) com CAAE: 51307115.9.0000.5166 e Parecer n. 1.400.662.

\section{Resultados e Discussão}

A partir das narrativas dos participantes emergiram duas categorias temáticas: "Identificação e denúncia dos casos de violência doméstica contra a mulher" e "Acolhimento e direcionamento da equipe frente à violência doméstica contra à mulher".

\section{Identificação e denúncia dos casos de violência doméstica contra a mulher}

A identificação dos casos de violência contra as mulheres pelos participantes do estudo parece ser uma tarefa complexa e limitante, já que por um lado há invisibilidade de notificação de violência e por outro há falta de entendimento quanto à abordagem e direcionamento dessas mulheres.

\footnotetext{
Acho que o difícil em si é o caso de identificar primeiramente, você não faz nada se você não identifica o problema, e muitas vezes no dia a dia, você percebe que não tem sempre essa brecha para que a mulher se sinta confortável, as vezes para poder tá falando né, se expondo, o que acontece dentro de casa [...]. (P6)

Em todas unidades de maneira geral a gente sente dificuldade em detectar em primeiro caso a violência doméstica. Se você não tiver uma aproximação, um vínculo com a família para que tenha essa abertura, você não fica sabendo [...]. (P8)
}

Nessa perspectiva, as narrativas corroboram com estudo realizado na Espanha, no qual evidenciou que os encontros entre as mulheres expostas ao companheiro violento e os profissionais são insatisfatórios, devido às inúmeras barreiras, especialmente pelas fragilidades no atendimento dos serviços de saúde bem como falta de qualificação para o pro- 
cesso de abordagem e acolhimento das vítimas (GOICOLEA et al., 2017).

Entre essas fragilidades, destaca-se a dificuldade em notificar com maior condição e frequência as situações além daquelas conhecidas pelas lesões físicas (hematomas, esganadura, queimaduras e fraturas), já que para alguns pesquisadores a existência de lesão visível é o principal meio de constatar a violência doméstica e familiar contra a mulher (SILVA et al., 2015a).

Verifica-se em estudo realizado na Índia, que o tipo mais comum de violência doméstica contra a mulher é a física, porém os profissionais de saúde desse país relatam que sempre vem acompanhada da violência psicológica (SHARMA, 2015). No entanto, conforme estudo realizado no Canadá, a atenção a saúde mental dos envolvidos nos casos de violência é uma questão relativamente pouco estudada e, muitas vezes, negligenciada pelos profissionais de saúde (DELARA, 2016).

Assim, ainda que se vislumbre a necessidade de treinamentos e implantação de programas de educação continuada/permanente junto aos profissionais e serviços de saúde, a intervenção/identificação dos casos de violência contra a mulher exige recursos que extrapolam o aspecto técnico-científico do profissional e gerencial das unidades. Observa-se que a maioria das vítimas deixam de buscar atendimento/ ajuda, por temerem as consequências frente ao ato de denunciar o agressor, a fragmentação familiar e, muitas vezes, se veem sozinhas para esse enfrentamento e sem apoio do serviço (SANTOS et al., 2017).

Esse cenário, aponta para necessidade de criação de novas formas de buscar/acolher essa mulher na comunidade, com o fortalecimento e a interação de todos da equipe é fundamental. No estudo, foi dado ênfase ao papel dos Agentes Comunitários de Saúde (ACS) nesse processo de auxílio na identificação de casos.

[...] os ACS conseguem fazer essa varredura de gravidade social, eles desenvolvem vínculo [...]. (P2)

Em questão de identificação, que a gente já teve alguns casos suspeitos, seria mais na questão através do Agente de Saúde [...]. (P7)

O ACS é um profissional que integra a equipe de saúde, sendo visto como um elo de grande relevância entre a comunidade e a unidade de saúde, por apresentar condições de promover um cuidado diferenciado aos seus usuários, ao realizar visitas domiciliares e utilizar de uma linguagem compreensível (MACIAZEKI-GOMES et al., 2016; NASCIMENTO et al., 2017a). E o fato de que o ACS deve, obrigatoriamente, residir em sua área de trabalho favorece a proximidade com a dinâmica das famílias, principalmente com as mulheres que são os principais contatos familiares a que tem acesso nas visitas domiciliares, permitindo reconhecer e se certificar da existência de iniquidades e desajustes sociais (NASCIMENTO, et al., 2017b).

Estudo realizado em Maceió (AL) sobre a conduta de ACS diante dos casos de violência domiciliar e familiar, evidenciou que muitos desses profissionais presenciam esses casos e realizam a intervenção, ajudando e orientando as vítimas sobre as medidas a serem adotadas, mas apesar disso, o serviço não os prepara para agir de forma propositiva e sistematizada nessa assistência terapêutica (LIRA et al., 2012).

De forma geral, os profissionais de saúde se sentem inseguros e impotentes diante da assistência em situação de violência contra à mulher (KIND et al., 2013). Muitos deles, principalmente aqueles da Atenção Básica, expressam o medo em se envolver nessa área por se verem desprotegidos e alvos de vingança por parte do agressor, nos casos de denúncia (CRUZ et al., 2017).

[...] Em relação as ameaças a gente se sente mal, por que vem um pessoa que você não conhece, marca a sua cara, e você fica...eu me sinto mal porque eu fico com medo de andar sozinha [...]. (P4)

[...] Me sinto ameaçado em relação a isso [Violência doméstica], porque você não sabe como a pessoa pode reagir [...]. (P9)

Alguns profissionais hesitam em realizar uma assistência integral, já que estão expostos à ameaça ao conduzir os casos de violência, principalmente os profissionais que residem na área em que trabalham, por exemplo os ACS. A crença de grande poder do agressor e a sensação de ingovernabilidade gera medo tanto nas mulheres vítimas da violência como nos profissionais (SILVA et al., 2015a).

Além de enfrentarem dificuldades no manejo com os pacientes e os familiares em situações de violência, os profissionais convivem com o risco de também sofrerem violência em seus ambientes de trabalho, durante o desempenho de suas funções, causando danos à saúde do trabalhador (BORDIGNON; MONTEIRO, 2016).

Outra problemática sinalizada que permeia essa situação é a ocorrência de quebra de sigilo do autor da denúncia pelo órgão/serviço ouvidor. Motivo que pode colocar em risco o trabalho assistencial às vítimas e/ou contribuir para que a denúncia não seja realizada pelo profissional (ACOSTA et al., 2017).

[...] Olha o que está prejudicando bastante, agora nesse momento, pelo menos na última denúncia que a gente fez, é que as conselheiras não estão mantendo sigilo, estão denunciando de onde partiu a denúncia, estão falando quem são as pessoas, assim como fica a gente? fica difícil de trabalhar [...]. (P4)

Estudo destaca que a privacidade de informações sobre a saúde do paciente é um direito, em contrapartida, o sigilo das informações sobre estes usuários é um dever do profissional de saúde, sendo que qualquer informação sobre o atendimento do usuário em qualquer serviço de saúde, assim como resultados de exames e procedimentos diagnósticos ou terapêuticos, devem ser preservados e ser de exclusiva propriedade do paciente, garantindo a boa relação entre profissional-paciente (DIAS et al., 2013).

Vale ressaltar que a quebra do sigilo poderá acontecer em situações específicas, por exemplo nos casos de ordem judicial ou com a permissão dos sujeitos envolvidos. Contudo, durante a prática assistencial à vítima, o acontecimento poderá ser revelado somente em casos que houver a necessidade de apoio para prestar o atendimento à mulher (ACOSTA et al., 2017). Sendo assim, cale destacar a impor- 
tância da articulação e seriedade entre o serviço de saúde e os outros setores envolvidos na resolução do problema.

Em muitos casos, mesmo com a intervenção, a violência identificada persiste, pois, a individualidade de alguns profissionais e serviços assistenciais não são capazes de cobrirem todos os aspectos deste fenômeno, o que consequentemente impede o trabalho articulado em rede e a resolutividade dos casos (XAVIER; LOPES, 2016).

No presente estudo, essa articulação parece ocorrer harmoniosamente e alguns profissionais reconhecem a importância desse trabalho integrado.

[...] Então assim, teve visita de assistência social, teve visita da própria promotoria, do CREAS assim, conseguiu resolver [...]. (P1)

[...] porque nós temos um CRAS aqui próximo, que nos dá suporte, é efetivo. E também nós temos hoje o matriciamento ativo, que quando nós entramos em contato com o CAPS embora não seja uma característica, mais a gente pode né, usar em caso de transtorno emocional, nós temos esse contato, esse matriciamento, essa resposta. E temos a delegacia da mulher, que nós podemos ter esse respaldo de polícia mesmo, segurança [...]. (P2)

[...] Os outros órgãos atuam junto, mais o primeiro passo quando é menor, é denunciar no conselho tutelar, e mulher a gente orienta a ir na delegacia da mulher, a gente tem o endereço, e orienta para elas irem lá [...]. (P4)

[...] a gente entra em contato com o trabalho social da área para nós fazer uma visita, a gente também faz visitas domiciliares. Em relação ao trabalho social, em alguns casos, já nos deram resposta, e já até nos solicitaram outras visitas [...]. (P8)

As narrativas apontam a importância da articulação intersetorial, viabilizando o melhor enfrentamento da violência doméstica contra a mulher. Apesar disso, estudo realizado na África do Sul aponta que os serviços primários desenvolvem cuidados superficiais, fragmentados, mal coordenados, sem continuidade e desintegrados com outros dispositivos sociais (JOYNER; MASH, 2014).

No Brasil, há uma variedade de serviços voltados a acolher e prestar o atendimento necessário as mulheres vítimas de violência, como as delegacias das mulheres, casas de abrigo e centros de referência especializado, que surgiram na tentativa de dar suporte a estas usuárias, garantindo maior proteção e minimização de danos, mas esses serviços também carecem de inter-relações. $\mathrm{Na}$ área da saúde, a ESF é vista como uma porta de entrada favorável para a identificação de casos de violência, contudo, percebe-se o despreparo dos profissionais em lidar e reconhecer esse tipo de agravo (MENEZES et al., 2014).

A falta de respaldo profissional é vista pelos profissionais como um dos entraves para o acolhimento e acompanhamento dos casos de violência contra a mulher, sugerindo a falta de experiência profissional e curricular como uma das justificativas.

[...] principalmente nessa parte de saúde mental e violência que nós não temos tanto respaldo profissional, por que nós não tivemos tanta experiência lá na grade curricular da faculdade [...]. (P2)
Algumas literaturas enfatizam a falta de aptidão dos profissionais de saúde em lidar com esses casos de violência doméstica, seja na ausência de conhecimento sobre os sinais de sofrimento (SCHEK et al., 2016) ou por não terem vivenciado esse conteúdo/experiência durante a formação acadêmica (KIND et al., 2013).

Em estudo realizado na Malásia, médicos da atenção básica confirmam que encontram dificuldades na identificação e intervenção dos casos, visto que existe uma carência de confiança e saberes por parte do profissional, em lidar com essas situações, gerando uma barreira na prática clínica (MYDIN; OTHMAN, 2017).

E por não se sentirem preparados para esse atendimento ou abordagens, grande maioria dos profissionais não identificam essas mulheres vítimas de algum tipo de violência, tampouco fazem registros. Essa ocultação na assistência amplia a imperceptibilidade dos casos, dificultando o conhecimento do panorama real desse agravo e, consequentemente, influencia nas ações de intervenção (GOMES et al., 2015).

\section{Acolhimento e direcionamento da equipe frente à violên- cia doméstica contra a mulher}

O acolhimento é um conceito utilizado para expressar as relações existentes entre os usuários e os profissionais de saúde envolvidos no cuidado, não se tratando somente da prestação do cuidado, mas da escuta qualificada e humanizada. Porém, no presente estudo, verifica-se que há um despreparo desde a identificação da ocorrência da violência até o acolhimento às mulheres, o que leva muitas vezes ao subregistro de casos. E, quando surge a demanda, os profissionais optam, prioritariamente, pelo encaminhamento para serviços de referências antes mesmo do primeiro contato.

[...] encaminha para psicólogos, mais aqui a gente não trata, não resolvemos o caso [...]. (P1)

[...] nós podemos participar ativamente como Unidade de Saúde da Família prestando essa assistência, então acho que a principal dificuldade é por que não tem tanto [Casos de violência], nós não temos essa realidade, então acaba não tendo essa prática constante [...]. (P2)

Ao contrário do que observado nas narrativas, diante de um caso de violência doméstica contra a mulher, é necessário a atuação integral da equipe durante o acolhimento. Esse cuidado abrange a escolha do local que ocorrerá o atendimento, de modo a oferecer segurança, privacidade e até mesmo a garantia do sigilo das informações colhidas (SILVA et al., 2015a).

Nessa perspectiva, estudo realizado na Espanha enfatiza que durante a abordagem dessas mulheres, a equipe de saúde deve prover apoio imediato às vítimas, baseando-se sempre nos recursos disponíveis, de modo a desenvolver um plano de segurança eficaz e isento de eventualidades. Desse modo, é importante salientar a efetividade no atendimento, instituindo a capacitação dos profissionais com o uso de técnicas para identificar os casos de acordo com a demanda apresentada, seguido de encaminhamento da vítima aos serviços articulados de apoio à ESF, que possam garantir a continuidade da assistência por meio do suporte multiprofis- 
sional especializado (RODRÍGUEZ-BLANES et al., 2017).

Nesse contexto, a Lei Maria da Penha é vista como uma das medidas utilizadas para melhorar a efetividade no combate em casos de violência doméstica, promovendo a proteção dos direitos da mulher e influenciando diretamente no aumento de denúncias com identificação do agressor (AMANCIO et al., 2016).

Muitas mulheres, após o atendimento inicial no local onde buscaram a primeira escuta procuram outros serviços de saúde pelo mesmo problema, o que sugere que o acolhimento não ocorre adequadamente ou há negligência na recepção de suas demandas (GARCIA et al., 2016). A OMS também reconhece esta falha existente e reforça a necessidade de aperfeiçoar a capacidade dos serviços em identificar precocemente os casos de violência contra a mulher e o risco de ocorrência de feminicídio. E deste modo, reforça que o adequado encaminhamento da mulher violentada e, o seu acesso aos serviços de referência podem fazer a diferença entre a vida e a morte (WHO, 2013).

Outro problema identificado no estudo, foi em relação à notificação dos casos, visto que muitos profissionais encontram dificuldades em comunicar formalmente já que grande parte das mulheres não fornecem os dados. No entanto, verifica-se que os profissionais possuem consciência da importância da notificação.

[...] só que elas tem medo de notificar, quando eu falo que vou fazer a notificação da violência doméstica, o porquê, que é somente para dados, e assim, a gente começa ir pra parte mental dessa parte doméstica [...]. (P6)

[...] tem a ficha de notificação, mais na hora que você vai preencher a pessoa não quer ter fornecer dados...já aconteceu isso, e como você notifica se a pessoa se nega a te dar informação?[...]. (P7)

[...] violência contra a mulher, tive uma vez só um caso, e a pessoa não quis levar adiante [...]. (P8)

A notificação deve ser vista como uma ferramenta para garantia dos direitos e proteção das mulheres vítimas da violência doméstica, permitindo a todos os profissionais e serviços envolvidos no caso adotarem medidas adequadas (GARBIN et al., 2015). Entretanto, a OMS evidencia que somente $2 \%$ dos casos são notificados pelos profissionais (SCHEK et al., 2016).

Esse fato pode estar relacionado à opressão sentida pelas mulheres, pelo medo/receio em dar visibilidade ao caso e frente a possíveis retaliações, o que interfere diretamente em sua qualidade de vida, em especial pelos danos emocionais causados. Tais consequências, são comumente negligenciadas pelos profissionais da atenção primária, pois em geral o cuidado volta-se aos sinais físicos, nitidamente visíveis. Diante disso, os profissionais devem ampliar sua disposição e investimento na capacidade investigativa, o que pode modificar o cenário de descaso aparentemente percebido na atenção às famílias em vulnerabilidade para violência doméstica (SILVA et al., 2015b).

Em relação ao profissional, as dificuldades enfrentadas no processo de notificação podem estar associadas à inúmeras causas, entre elas a falta de preparo; a falta de credibilidade nos serviços de proteção; descrédito na responsa- bilização dos agressores; receio relacionado aos procedimentos legais que podem ser exigidos, como prestar depoimento ou comparecer em uma audiência; medo de ameaças e a insegurança pela falta de habilidades para lidar com a diversidade de situações (FARAJ; SIQUEIRA, 2016).

Nesse âmbito, Veloso et al. (2017) ressaltam em seu estudo, que os profissionais reconhecem sua obrigação quanto à notificação da violência, assim como sabem identificar os principais sinais e a rede de referência, mas o tema violência não tem importância nas discussões das equipes de saúde, tampouco é colocado como prioridade na assistência pelos gestores e os próprios profissionais, o que influencia nas condutas quanto à identificação, notificação e intervenção diante dos casos.

Quando o profissional possui conhecimento e atitude em notificar e conduzir o caso de violência contra a mulher, este esbarra no impedimento da vítima em dar continuidade aos procedimentos.

[...] É difícil depois a gente acompanhar [acompanhar o caso], pois a mulher geralmente volta pro homem que a violentava pela dependência financeira, são poucas as que não precisam deles, e que podem ficar realmente sem o homem, elas acaba voltando ou por carência afetiva ou pela carência financeira [...]. (P4)

[...] elas preferem ainda aguentar, continuar casadas, as vezes ainda se sujeitar a algumas coisas [...]. (P6)

[...] tem violência psicológica, muitas mulheres são submissas, são coisas terríveis, você sabe que aquilo é um tipo de violência, mais elas não veem como violência [...]. (P8)

Estudo realizado em Hong Kong, demonstra que o número de episódios de violência de gênero prevê o comportamento de busca de ajuda pelas vítimas, sendo que dois ou mais incidentes de violência aumentam a procura por assistência (CHOI et al., 2018). Mas, percebe-se que muitas mulheres mesmo sofrendo, ou até mesmo por já terem sofrido algum tipo de violência, preferem continuar com seus companheiros, assim como, há vários casos, porém pouco mencionados de mulheres de classe alta que escolhem ficar em uma relação de conflito pelo status social que o matrimônio representa (OLIVEIRA et al., 2015).

Verifica-se também que a carência afetiva pode influenciar a mulher na manutenção deste ciclo vicioso, privando-as da liberdade e autonomia em assumir posicionamentos que garantam sua dignidade enquanto mulher e seu valor enquanto ser humano (OLIVEIRA et al., 2015), tendo o profissional um papel fundamental no auxílio às mulheres, inserindo-as em grupos terapêuticos, realizando intervenções domiciliares e oferecendo suporte emocional, na intenção de contribuir com a reconquista de seus espaços perdidos e direitos violados.

Todavia, depois desse investimento assistencial, há manifestação de um tipo de arrependimento pelo profissional, como se a expectativa depositada à vítima depois do cuidado oferecido, fosse frustrada ao deparar com a reconciliação da mulher com agressor.

[...] Você só atende aquilo que ela precisar, dá aquele apoio, mais se ela não quiser ir em frente, ela vai voltar 
para o marido, para que então fazer tudo isso? [...]. (P7)

Diante da falta de resolutividade do fato, os profissionais sentimentalizam-se negativamente, por perceberem sua atuação restrita aos desejos e decisões da mulher e até do sistema judiciário. É rotineiro alguns profissionais vivenciarem o sentimento de angústia e decepção ao observarem como os casos evoluem (VIEIRA et al., 2017).

Mesmo passando por atendimentos em que são orientadas sobre a ocorrência de um ciclo vicioso, essas mulheres necessitam integrar redes de apoio, a fim de auxiliar no processo de resgaste de suas autonomias e emancipação dentro dos lares, de modo que esse fortalecimento e reflexão sobre sua condição de vida e perspectiva de futuro não as deixe perpetuar reiteradamente novas ocorrências de violência.

Sendo assim, cabe aos profissionais de saúde, entenderem o sofrimento dessas mulheres e suas experiências de desigualdade de gênero nas relações familiares, o que pode atenuar possíveis sensações de insucesso frente à assistência nos casos de violência doméstica. Em contrapartida, há importância de intensificar as ações de prevenção na comunidade, capacitar as equipes para identificação precoce de contextos violentos, realizar o acolhimento humanizado e melhorar a escuta ativa dos profissional nas situações de denúncias e notificações.

\section{Considerações finais}

Com o estudo, foi possível evidenciar algumas dificuldades encontradas pelos profissionais de saúde pertencentes a ESF, na identificação de casos de violência doméstica, assim como os enfrentamentos vivenciados durante o acolhimento e o acompanhamento de vítimas, as ameaças sofridas por estes profissionais e o conhecimento fragilizado de alguns, em lidar com os casos de violência. Há contradições entre o atendimento preconizado nos casos de violência e como estas vítimas são acompanhadas pelos profissionais que as atendem. Em suas vivências, os profissionais relatam sentimentos de medo ao lidarem com esses casos, já que na grande maioria são eles os responsáveis pelas denúncias.

Os profissionais de saúde podem minimizar os déficits existentes na assistência destas vítimas. Para tanto, novas estratégias devem ser repensadas, de modo que haja acompanhamento sistematizado de todo o processo desde a escuta inicial até o desfecho do caso.

Entre as limitações do estudo, destaca-se a recusa dos profissionais médicos em participar da pesquisa e a inclusão somente de uma modalidade de serviço de saúde. Portanto, sugere-se que novos estudos, em distintas realidades e contextos que explorem a identificação e acolhimento dos casos de violência doméstica contra a mulher.

\section{Referências}

ACOSTA, D. F. et al. Aspectos éticos e legais no cuidado de enfermagem as vítimas de violência doméstica. Texto Contexto Enferm., v. 26, n. 3, p. 1-9, 2017.

AMANCIO, G. R. et al. Análise da efetividade da Lei Maria da Penha e dos Conselhos Municipais da Mulher no combate à violência doméstica e familiar no Brasil. Textos Contextos, v. 15, n. 1, p. $171-183,2016$.

BARDIN, L. Análise de conteúdo. São Paulo: Edições 70, 2011.

BORDIGNON, M.; MONTEIRO, M. I. Violência no trabalho da Enfermagem: um olhar às consequências. Rev. Bras. Enferm., v. 69, n. 5, p. 996-999, 2016.

BRASIL. Ministério da Justiça. Lei Maria da Penha - Lei $\mathrm{n}^{\circ}$ 11.340, de 7 de agosto de 2006. Diário Oficial da União, 2006.

CHOI, A. W. M. et al. Intimate partner violence victims' acceptance and refusal of on-site counseling in emergency departments: Predictors of help-seeking behavior explored through a 5-year medical chart review. Prev. Med., v. 108, p. 86-92, 2018.

CRUZ, S. T. M. et al. Violência de Gênero e seus Autores: Representações dos Profissionais de Saúde. Psico-USF, v. 22, n. 3, p. 555-567, 2017.

DATASUS. Departamento de informática do Sistema Único de Saúde. Mortalidade em mulheres por Agressão. (2017). Disponível em: <http://tabnet.datasus.gov.br/cgi/tabcgi. exe?sim/cnv/pobt10uf.def $>$. Acesso em: 03 fev. 2018.

DELARA, M. Mental health consequences and risk factors of physical intimate partner violence. Ment. Health Fam. Med., v. 12, p.119-25, 2016.

DIAS, O. V. et al. Segredo profissional e sua importância na prática de enfermeiros e odontólogos. Rev. Bioét., v. 21, n. 3, p. 448-454, 2013.

FARAJ, S. P.; SIQUEIRA, A. C. Notificação da Violência: Percepções de Operadores do Direito e Conselheiros Tutelares. Psicol. ciênc. prof., v. 36, n. 4, p. 907-920, 2016.

FONSECA, D. H. et al. Violência doméstica contra a mulher: realidades e representações sociais. Psicol. soc., v. 24, n. 2 , p. 307-314, 2012.

FONTANELLA, B. J. B. et al. Amostragem em pesquisas qualitativas: proposta de procedimentos para constatar saturação teórica. Cad. Saúde Pública, v. 27, n. 2, p. 388394, 2011.

GARBIN, C. A. S. et al. Desafios do profissional de saúde na notificação da violência: obrigatoriedade, efetivação e encaminhamento. Ciênc. Saúde colet., v. 20, n. 6, p. 1879$1890,2015$.

GARCIA, L. P. et al. Avaliação do impacto da Lei Maria da Penha sobre a mortalidade de mulheres por agressões no Brasil, 2001-2011. Epidemiol. Serv. Saúde, v. 22, n. 3, p. 383-394, 2013.

GARCIA, L. P. et al. Violência doméstica e familiar contra a mulher: estudo de casos e controles com vítimas atendidas 
em serviços de urgência e emergência, 2001-2011. Cad. Saúde Pública, v. 32, n. 4, p. 1-11, 2016.

GOICOLEA, I. et al. Why do certain primary health care teams respond better to intimate partner violence than others? A multiple case study. Gac. Sanit., 2017. https://doi. org/10.1016/j.gaceta.2017.10.005

GOMES, N. P. et al. Enfrentamento da violência conjugal no âmbito da estratégia saúde da família. Rev. enferm. UERJ, v. 22 , n. 4, p.477-81, 2014.

GOMES, V. L. O. et al. Domestic violence against women: representations of health professionals. Rev. Latino-Am. Enferm., v. 23, n. 4, p. 718-724, 2015.

GREIN, T. A. D. et al. Violência doméstica contra mulheres: produção de sentidos pela mídia televisiva no sudoeste de Mato Grosso, Brasil. Rev. Bras. Pesq. Saúde, v. 18, n. 2, p. 87-95, 2016.

IBGE. Instituto Brasileiro de Geografia e Estatística. Pesquisa por População Estimada no Município de Tangará da Serra - Mato Grosso (2017). Disponível em: $<$ https://cidades.ibge.gov.br/brasil/mt/tangara-da-serra/ panorama>. Acesso em: 29 jan. 2018.

JOYNER, K.; MASH, B. Quality of Care for Intimate Partner Violence in South African Primary Care: A Qualitative Study. Violence vict., v. 29, n. 4, p. 652-69, 2014.

KIND, L. et al. Subnotificação e (in)visibilidade da violência contra mulheres na atenção primária à saúde. Cad. Saúde Pública, v. 29, n. 9, p. 1805-1815, 2013.

LIMA, L. A. de A. et al. Assistência de enfermagem às mulheres vítimas de violência doméstica. Rev. Enferm. UFPI, v. 6, n. 2, p. 65-68, 2017.

LIRA, C. E. P. R. et al. Conduta dos agentes comunitários de saúde diante de casos de violência familiar. Rev. Eletr. Enf., v. 14, n. 4, p. 928-936, 2012.

MACHADO, M. E. S. et al. Percepção de profissionais de saúde sobre violência contra a mulher: estudo descritivo. Online braz. j. nursing, v. 16, n. 1, p. 209-217, 2017.

MACIAZEKI-GOMES, R. C. et al. O trabalho do agente comunitário de saúde na perspectiva da educação popular em saúde: possibilidades e desafios. Ciênc. Saúde Colet., v. 21, n. 5, p. 1637-1646, 2016.

MATO GROSSO. Assembleia Legislativa do Estado de Mato Grosso. Ações para combater a violência contra a mulher são definidas em audiência pública. Cuiabá, 2018.

MENEZES, P. R. M. et al. Enfrentamento da violência contra a mulher: articulação intersetorial e atenção integral. Saúde Soc., v. 23, n. 3, p. 778-786, 2014.

MUSSE, J. O. et al. Atuação do enfermeiro perante a violência doméstica sofrida pelo idoso. Estud. interdiscipl. envelhec., v. 20, n. 2, p. 365-379, 2015.

MYDIN, F. H. M.; OTHMAN, S. Elder Abuse and Neglect Intervention in the Clinical Setting: Perceptions and Barriers Faced by Primary Care Physicians in Malaysia. J. Interpers. Violence, p. 1-26, 2017.

NASCIMENTO, V. F. et al. Dificuldades apontadas pelo agente comunitário de saúde na realização do seu trabalho. Saúde (Santa Maria), v. 43, n. 1, p. 60-69, 2017.

NASCIMENTO, V. F. et al. Percepção de agentes comunitários de saúde sobre visita domiciliária após aperfeiçoamento em saúde da família. Rev. APS, v. 20, n. 3, p. 392-402, 2017.

OLIVEIRA, P. P. et al. Mulheres vítimas de violência doméstica: uma abordagem fenomenológica. Texto Contexto Enferm., v. 24, n. 1, p. 196-203, 2015.

OLIVEIRA, M. C. B. et al. Atendimento de mulheres vítimas de violência doméstica em um serviço de urgência e emergência. Braz. J. Surg. Clin. Res., v. 21, n. 3, p. 43-48, 2018.

RODRÍGUEZ-BLANES, G. M. et al. Detection of intimate partner violence in primary care and related factors. Gac. Sanit., v. 31, n. 5, p. 410-415, 2017.

SANTOS, D. F. et al. Percepção de mulheres acerca da violência vivenciada. Rev. Fund. Care Online, v. 9, n. 1, p. 193-199, 2017.

SCHEK, G. et al. Os profissionais e a violência intrafamiliar contra crianças e adolescentes: entre os preceitos legais e conceptuais. Rev. Esc. Enferm. USP, v. 50, n. 5, p. 780-785, 2016.

SHARMA, I. Violence against women: Where are the solutions? Indian J. Psychiatry. v. 57, n. 2, p. 131-139, 2015 .

SILVA, C. D. et al. Representação social da violência doméstica contra a mulher entre Técnicos de Enfermagem e Agentes Comunitários. Rev. Esc. Enferm. USP, v. 49, n. 1, p. 22-29, 2015.

SILVA, S. A. et al. Análise da violência doméstica na saúde das mulheres. Rev. bras. crescimento desenvolv. hum. v. 25 n. 2, p. 182-186, 2015.

VELOSO, M. M. X. et al. Identificação e notificação de violência contra crianças e adolescentes: limites e possibilidades de atuação de profissionais de saúde. Mudanças, v. 25, n. 1, p. 1-8, 2017.

VIEIRA, E. M. et al. Percepções dos profissionais de uma rede intersetorial sobre o atendimento a mulheres em situação de violência. Interface (Botucatu), v. 21, n. 60, p. 51-62, 2017. 
XAVIER, P. R. H.; LOPES, S. M. B. As práticas do Assistente Social e sua articulação com a Equipe de Saúde de um Hospital de Curitiba. Serv. Soc. Rev., v. 18, n. 2, p. 132-150, 2016.

WHO. World Health Organization. Responding to intimate partner violence and sexual violence against women:

WHO clinical and policy guidelines. Geneva: World Health Organization, 2013.

Recebido em: 27/02/2018

Aceito em: 11/07/2018 